\title{
Quo vadis, NASA?
}

\author{
NASA's space shuttle programme is at an end - as may be the funding for its next space telescope.
}

With the final flight of the space shuttle Atlantis last month, US primacy in the race to space is on the wane. Although NASA officials have stated their confidence in the future of manned spaceflight, missions to low Earth orbits will probably now fall to private enterprise - and to other nations such as China and India, who, although later entrants in the space race, are still keen competitors.

\section{"In many fields of astronomy we are rapidly approaching the limit of what can be done without JWST." \\ Julianne Delcanton}

NASA's Apollo programme is remembered fondly, having met President Kennedy's challenge of putting men on the Moon before the end of the 1960s, and before the Russians could do so. The space shuttle - chosen as Apollo's successor by the Nixon administration in 1972 inspires more mixed feelings. Amid the commemorations of the fleet's retirement, Robert Park of the University of Maryland, College Park, told Science that the shuttle "indulged humankind's impractical space fantasies" $(333,29 ; 2011)$. Writing in Technology Review, John M. Logsdon analyses whether the programme was a mistake, and concludes that the choice of the ambitious and complex shuttle design was the wrong one; that simpler technology, to be superseded by a second-generation design, would have been the better - and cheaper - way forward (http://www. technologyreview.com/computing/37981).

The record of achievement for 30 years of expensive shuttle missions is also patchy, and the science payback from onboard experiments has been lacking. The shuttle has, however, been an indirect player in some of the great astronomical successes of recent decades as the launch vehicle for instruments including the Compton gamma-ray and Chandra X-ray observatories and the Hubble Space Telescope (the latter famously the subject of several repair and maintenance missions). All three have returned stunning images of the Universe a mere handful of which are pictured here.

The end of the shuttle programme, with no replacement planned, leaves NASA in a challenging position if it intends to remain a leader in space exploration. There is no shortage of ideas among astrophysicists for unmanned missions, although in recent years much of the funding for such projects has been sacrificed to pay for what would be the centrepiece of NASA's future: Hubble's bigger, better successor, the James Webb Space Telescope (JWST). But now the JWST is under threat. The House appropriations bill, tabled last month, calls for a \$1.6 billion cut in NASA's budget, and explicitly "terminates funding" for the JWST, which is deemed to be "billions of dollars over budget and plagued by poor management".

There will now follow months of wrangling among politicians before the bill might be passed. There is no denying that the JWST is running behind schedule and over budget, and there is indeed the precedent of the Superconducting Supercollider, which was under construction in Texas when it was killed by the US Congress for similar reasons of expense and mismanagement. Billions of dollars have already been sunk into the JWST, but this in itself is not sufficient reason to continue. However, by stopping the telescope, the USA risks leaving its international project partners in Canada and Europe high and dry, and possibly reluctant to share in other, future plans. Worst of all will be the loss to science. As Julianne Delcanton wrote on the blog Cosmic Variance, "in many fields of astronomy we are rapidly approaching the limit of what can be done without JWST".

Mismanagement cannot be excused these are no longer the indulgent days of the early space race. Budgeting must be realistic and flexible, taking good account of the difficulties of seeing through a project that may span decades and involve international partners. It can be done: witness the success of the Large Hadron Collider (a programme not without its own hiccups in coming to fruition). It makes no sense to kill the JWST, but the threat, if seen off, should galvanize efforts to meet a launch date within the next decade.

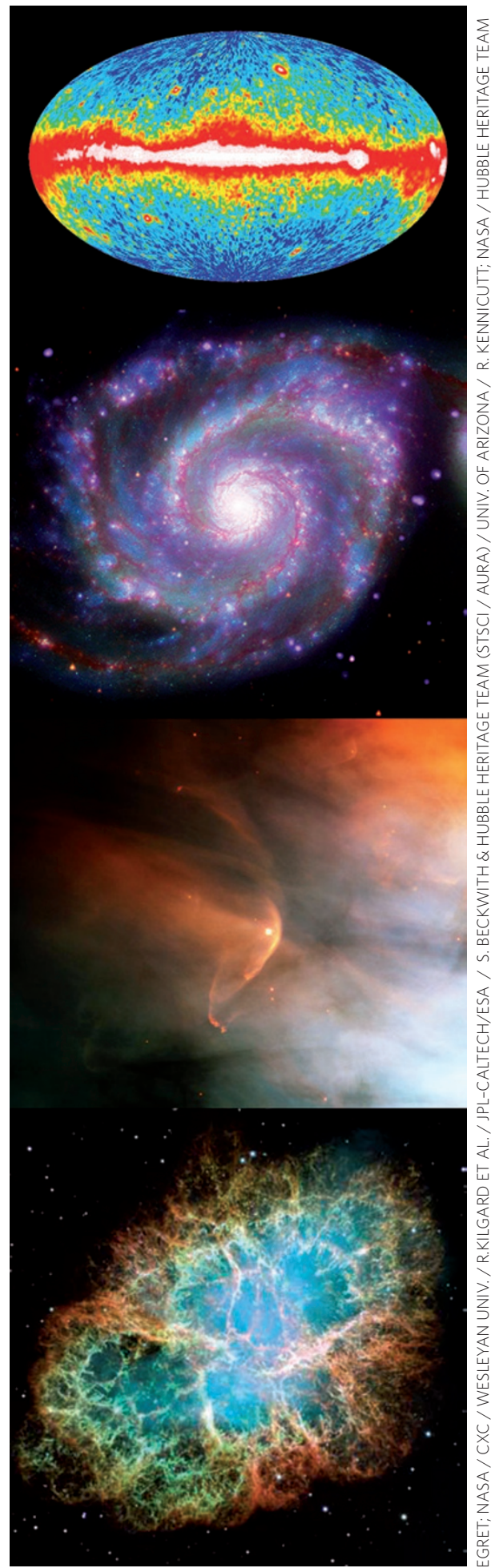

